whether of the stomach, liver, or kidneys, whose digestive organs (so essential to the nutrition, growth, and repair of the system) are irritated and inflamed by the use of intoxicating drinks, can not be expected to respond to any treatment, however judicious and appropriate. $^{2}$ In. such subjects there is great tendency to irritability of stomach; the purgatives are not retained, the inflammatory stage (fever) runs high, and can not be subdued. Congestion of the internal organs, kidneys, etc., with albuminuria, occurs; black vomit sets in; and uremic poisoning, with coma, generally closes the scene-during attacks of violent convulsions. Under such conditions, all agents prove nugatory; every effort is necessarily unavailing; and these cases-falsely and illogically reasoned from-bring reproach upon true and legitimate treatment, which can be shown to be serviceable in those who, from the beginning, are not plainly beyond the reach of art.

In my humble judgment, if not the height of folly, it is at least extremely unfair to decry or, which is worse, to abandon, a course of management which is eminently and strikingly successful in nearly or quite all the cases of the class previously described, because it fails to cure those who have no right to expect a miracle to be worked in their behalf.

Any treatment which is successful is not so by accident, but because it is based upon the requirements and real nature of the disease and throughout does the patient no harm. It is high time for the intelligent members of our profession, particularly if they be at all apathetic, to give up the pleasing idea that the practice of physics is all guesswork, in which one artist does full as well as another; that fate and the disease have the control, and that always when a child or man dies the "physician who heals is Death."

\section{THE CAISSON EXPLOSION OF BATTERY F, SECOND REGIMENT OF THE U.S. LIGHT ARTILLERY.}

BY EDMUND ANDREWS, A.M., M.D., LL.D.

FORMER SURGEON OF FIRST REGIMENT OF ILLINOIS LIGHT ARTILLERY; PROFESSOR OF CLINICAL SURGERY IN MERCY HOSPITAL, ETC.

The writer is at present in charge of a number of soldiers wounded by an accident so rare, that hardly any officer in the United States service has seen an example of it.

The singular character of the wounds produced, and the rarity of the causes producing them, render the cases most instructive for study.

The late riots in Chicago, by obstructing the United States mails, and arresting commerce on interstate railways obliged the general government to send to Chicago about 2,000 regular troops to maintain order.

On the 16th of July, Battery F of the Second Regiment of U.S. Light Artillery was moving at a trot on Grand Boulevard, supported by a company of the Seventh Regular Cavalry, when suddenly the three ammunition chests of the first caisson exploded with terrific violence.

The caisșon was drawn by four horses, which were guided by two mounted drivers. Two cannoneers sat on the limber, or forward chest, but fortunately there were no soldiers on the two others. Two sergeants were riding beside the column, and also part of the

\footnotetext{
2 "There is no hope for the drunkard." $-\mathrm{S}$. H. Dickson.
}

cavalry escort. A number of citizens were on the sidewalks, and at the doors and windows of the adjacent houses.

The two cannoneers on the limber were literally blown to pieces and the fragments scattered hundreds of feet. Two of the mounted men were also killed, and fifteen men were wounded. Three citizens received injuries. Nine horses were killed.

The singular character of the wounds will be noted below.

There were 126 cartridges of cannon powder in the chests amounting to over 400 pounds, besides a large number of shrapnel, and other loaded shells.

The subjoined cuts, and some of the facts about the nature of the shells, etc., are from an article furnished to the Chicago Tribune by an educated military officer.

There were two kinds of projectiles in the caisson; one, the simple steel shell with a time fuse. These were all picked up afterwards unexploded. The other kind were the complicated shrapnels which have percussion as well as time fuses, and exploded all

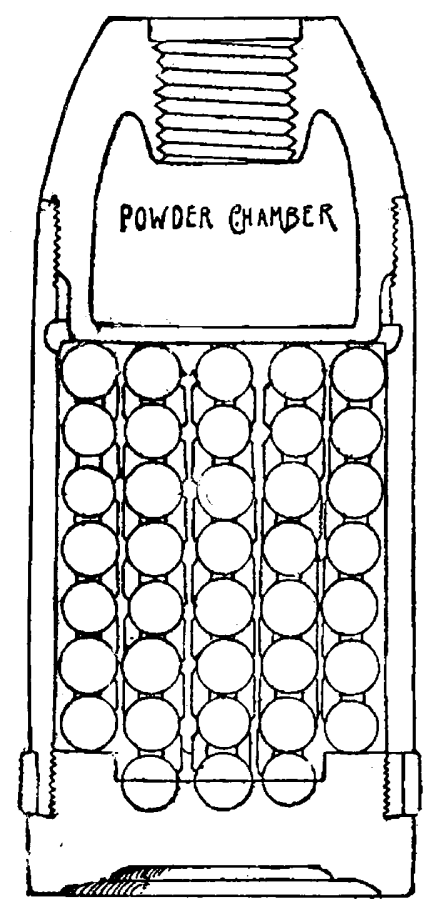

Fig. 1.-Longitudinal section of shrapuel.

about wherever they struck the ground. The shrapnel shell is named from its inventor, Gen. Shrapnel. Fig. 1 shows a longitudinal section of one.

The top of the shell is closed by a metallic plug screwed in and containing a complicated arrangement for firing the powder in the shell, whenever it strikes, or sooner if desired. Below the plug is a chamber filled with a small charge of powder-two and three-fourths ounces-just enough to burst the shell as it flies toward the enemy, while the pieces spread out in the form of a cone and continue on their course, making awful destruction. Below the powder chamber there is a larger cavity containing 162 lead bullets mixed with rings of cast iron. The bullets, added to broken rings and fragments of shell make for each shell over 300 pieces of metal to be shot fiercely into the faces of the enemy.

Experiments made to determine the effect on a target showed that the flying pieces pierced the wood 
so closely that there was hardly a spot as big as two hands which had not been struck. It is one of the most terrific instruments of war.

Fig. 2 is a transverse section of the bullet chamber.

Fig. 3 shows the cast-iron rings for holding the bullets steady.

It will be observed that in shrapnel the bursting charge is small, so that when a stationary shell explodes, the pieces do not fly laterally with great velocity. The terrible effects in war are caused by the forward velocity given by firing the shell from the cannon. In the present case the shells were not "fired from the gun and hence though fifty-three of them exploded, few of the wounds contained any bullets or pieces of iron.

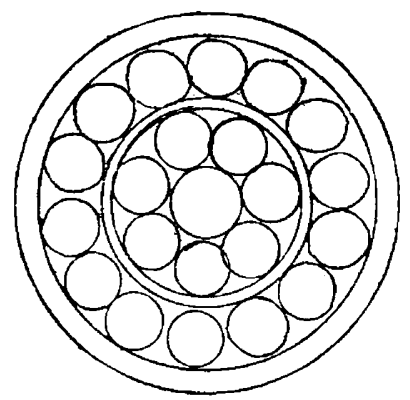

Fig. 2.-Transverse section showing the arrangement of balls.

The remarkable feature in the injuries placed under my care is that nineteen-twentieths of the wounds were made by the big unconsumed grains of modern cannon powder which are nearly half an inch in diameter and penetrate like bullets. Those who were most severely injured were under too much shock to bear transportation to the distant camp, hence five were brought to me in Mercy Hospital, and one to Prof. E. W. Andrews at Michael Reese Hospital.
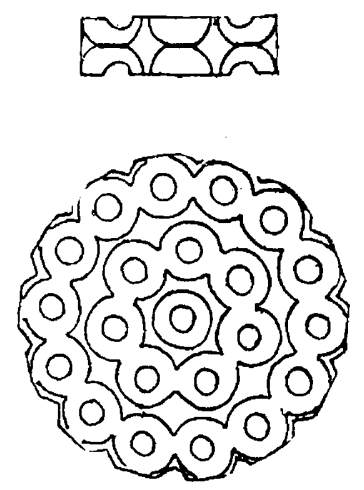

Fig. 3.-Cast-iron rings.

The latter soldier, Private Stoltz, sat on his horse in front of the exploding limber chest, receiving the projectiles in his back. The grains of cannon powder in the chest were large and irregular in form, averaging about the size of chestnuts. Thousands of them flew in every direction like bullets, some burning as they flew, and many probably not even on fire. Aside from the flying pieces of powder, a great globe of flame enveloped the whole area near the caisson. Stoltz's hands and the back of his neck were blistered by the flame. The parts covered by clothing escaped blistering but his entire back down to the line where the posterior elevation of the saddletree protected the nates, was perforated by hundreds of cannon powder masses, so that there was hardly room to touch him with the point of a finger without inserting it into one of the orifices. Generally the wounds penetrated about three-quarters of an inch and the surfaces were black and pulpy as if the connective tissue were half crushed and half burned. The grains themselves could not be found in definite form, either having been burned up in their beds, or else been softened by the blood into a paste. Some of the larger wounds contained broken chips of wood from the limber chest. One large piece of wood five inches long and an inch wide had pierced the skin endwise and lay along the seventh rib. No bullets nor pieces of iron were found, but some of the wounds were deep, and bullets or pieces of iron may have been in the interior depths. As he was in a dying condition thorough search was impossible. The patient was delirious and died in six hours of shock.

Sergeant L. Leiner was brought to Mercy Hospital suffering severe shock so that great fears were felt that he would not rally. However, in twenty-four hours he had pretty well reacted. At the time of the accident he was riding beside the column a little to the rear of the exploding caisson, so that he received the blast in front. His face and hands were blistered by the flame, the whole front of the body, from head to ankle was punctured with powder lumps similar to those of Stoltz, but fewer in number. Perhaps a hundred in all. One of the wounds penetrated through the rectus abdominis muscle, so that the finger could be inserted, but the peritoneum was not penetrated. Pieces of wood were extracted from that wound and from several others, but most of the orifices contained nothing tangible. One wound over the ligamentum patellæ allowed the finger to run up into the patellar bursa and the front of the bone was chipped. A piece of iron about half an inch long lay there, but the eapsule of the joint was not opened. He is now out of bed.

Private O'Donnell received the charge also in front, and had perhaps a hundred powder punctures. The shock was severe. The face and hands were blistered. One wound of some size was received on the eyebrow and others in various parts of the face and body. Several pieces of wood from the ammunition chests were extracted, and also a piece of copper, derived from the copper ring that encompasses the base of each shrapnel shell.

Trumpeter H. Antes, Seventh Cavalry, received numerous wounds over the front of the face and body, one of them chipping the end of the clavicle. Pieces of wood were found but no metal, yet he had apparently been struck by a large fragment of iron or wood, for the right deltoid muscle was torn away, the acromion process was shattered, the tuberosity of the humerus was carried away bodily and the shoulder-joint was laid open along its outer border. Several small pieces of wood and chips of bone were removed, but no metal. The wound extended behind the scapala below the spinous process. It was cleansed and dressed antiseptically. In a few days hewas removed to Fort Sheridan, where SurgeonMajor Girard exerted himself to get rid of all septic remnants of bruised flesh and crushed bone and then trimmed the flaps and brought up the renillant of the deltoid and sutured the flaps together, thus covering the wound and the opening of the joint, with an excellent prospect of saving the articulation from suppuration and ankylosis. 
The wounds of the other soldiers were similar in character.

One lady in an adjacent house had her arm cut, probably by flying pieces of glass.

Another lady received a projectile from a shrapnel cutting off the tendon of Achilles.

A boy of 14 years passing on a bicycle, received two shrapnel shots in the calf of the leg.

So far as I had opportunity to observe, none of these men received any injury to the globe of the eye, though their faces were perfectly peppered with wounds. This seems to show that the explosion was not absolutely instantaneous, since they had time to shut the lids before receiving the blast.

As to the rarity of this accident, it is well known that ammunition chests are occasionally exploded in battle when struck by the shells of the enemy, but to do so when simply traversing a smooth road is so unprecedented that only four cases are on record in the U.S. Army, and in only two of them are the facts clearly established. The investigations already ordered will doubtless discover the causes, and prevent such disasters in future.

2520 Prairie Avenue, Chicago.

TWO CASES OF INTESTINAL OBSTRUCTION.

Specimen presented and remarks made at a meeting of the Medical Society of the District of Columbia.

BY I. S. STONE, M.D.

SLRGEON TO COLUMBIA HOSPITAL, ETC., WASHINGTON, D. C.

Case 1.-R., colored, age 21 , had been sick three weeks with specific pelvic suppuration. She had no symptoms of intestinal obstruction or of nephritis. She had the usual preliminary treatment incidental to laparotomy for pyosalpinx. Salts were administered freely and acted well the day before operation. Her urine was examined on entering the hospital and again the day of operation and pronounced free from albumen. A microscopic examination was not made. The operation was made on June 6 at $10: 30$ A.M. Everything passed off in a satisfactory manner. Intestinal adhesions were not difficult to overcome. The patient was placed in the Trendelenburg posture and every precaution was taken to complete the operation in a thorough and satisfactory manner. The pelvis and lower abdomen was flushed with rather more than the usual care, as quite a large quantity of pus had escaped in the removal of the greatly distended pus sacs. A glass drain tube was placed as usual. Nothing unusual occurred after the operation until the next morning when the transverse colon was found distended greatly. The administration of enemas had but little effect in dislodging the collection of gas, and the stomach refused at first to retain fluids. Afterwards during the afternoon and evening of the day following operation, salts and castor oil were both retained in full quantity without overcoming the fatal obstruction. The patient did not suffer greatly from pain. There were few symptoms of peritonitis and, in fact, the prompt occurrence of the symptoms after operation did not suggest peritonitis as a cause of the distension. The drainage tube was removed in thirty hours and a long forceps with a piece of gauze was used in the drain tract to ascertain if the intestines were anywhere adherent. The forceps moved freely and easily, thus demonstrating the absence of pelvic peritonitis. At the autopsy this was proved correct, as there was only one point where the intestine was adherent, namely, to the pedicle on the right side.

The quantity of urine passed was estimated by the house physician at eight and one-half ounces during the forty hours the patient survived the operation. This decrease in the quantity of urine was thought due to the obstruction, and the kidneys were not thought diseased. Ether was used as the anesthetic but only a small quantity was required, as the patient very rapidly came under its influence.

The operation was not more difficult than usual, and was done with deliberation and care in every detail ia less than forty-five minutes. The patient died forty hours after operation. The autopsy six

hours later revealed two points where the intestine was occluded. One specimen shows the large bowel at junction of the transverse and descending colon just under the spleen. A stenosis exists at this point. Air could easily be forced through this narrow passage before the specimen was laid open by the paththologist. When the autopsy was made I thought this stricture might be due to change in the intestinal wall after the operation, or due to intestinal spasm. But the section plainly shows an organic stricture permeable during life when intestinal peristalsis was not diminished. But this was not the only source of obstruction. A diverticulum was found tightly drawn across the ileum about three inches above the cecum. The greatly distended ascending colon appeared to press the lower end of the small bowel forward and thus added to the twist of this diverticulum, which completely occluded the bowel at this point. The small intestine was distended with fluid and intestinal gas to this point. This diverticulum is two inches long, three-fourths of an inch wide at its central portion and gradually narrowing toward each end. It appears to be a congenital abnormality and much resembles an abortive mesentery or mes. enteric fold.

The theory of the case is somewhat as follows: After the operation very little flatus was forced through the lower stricture even with the aid of enemata. The transverse colon soon became distended causing pressure upon the stomach and displaced the diaphragm with heart upwards. Rapid and feeble heart action supervened and the patient had the appearance of secondary shock. The obstruction near the cecum did not permit the entrance of fluids into the large bowel, and in consequence the narrow structure of the colon would not yield to the feeble peristalsis of the distended bowel.

Still another element of unseen danger entered in to the combination which produced the fatal result. The quantity of urine was greatly diminished, and as above stated this was thought due to obstruction high up in the small intestine. At the autopsy, the explanation was found in the kidneys. Both kidneys present undoubted evidence of nephritis. This fact affords another instance of the very unreliable nature of our usual tests for this disease prior to surgical operations, and especially in view of the influence of ether upon the kidneys. The examination of the patient's urine was made upon two occasions by internes in whom I have perfect confidence as to integrity and capability. No albumen was found. Finally there would appear but slight probability that the nephritis in this case could be of only forty hours duration, or in other words be entirely due to the use of ether.

Washington, D. C., July 10, 1894.

Dr. I. S. Stone, 1504 H Street, N. W., Washington, D. C.:

Dear Doctor:-The specimens in the case of the colored girl, Ragland, consisting of the large intestine and kidneys, have been subjected to a microscopic examination in the laboratory of the Museum with the following results: The stricture at the junction of the transverse and descending colon shows, on section, marked thickening of the longitudinal and circular muscular coats of the bowel, as well as increase of the submucous layer. The mucous membrane lining the stricture was somewhat atrophied. From this examination 1 am led to believe that the stricture was organic in its nature, and probably congenital in origin. The kidneys show an advanced desree of fatty degeneration of the epithelium lining the secreting tubules, as well as that lining Bowman's capsules and covering the Mal- 